\title{
LA DOSIFICACIÓN DEL PASADO \\ la memoria en las políticas oficiales de reparación chilenas
}

\section{Juan Carlos Arboleda-Ariza}

E-mail: juan.arboleda@usco.edu.co

\section{Gabriel Prosser Bravo (2)}

E-mail: gabriel.prosser@uacademia.cl

(1) Universidad Surcolombiana, Programa de Psicología, Facultad de Ciencias Sociales y Humanas, Grupo de investigación Insurgentes, Neiva- Huila, Colombia.

(2) Escuela de Psicología, Universidad Academia de Humanismo Cristiano, Santiago, Chile.

DOI: $10.1590 / 3610604 / 2021$

\section{Introducción}

La Dictadura cívico-militar, comprendida desde el Golpe de Estado del 11 de septiembre de 1973 hasta el 10 de marzo de 1990, último día de gobierno del dictador Augusto Pinochet, es reconocida como uno de los capítulos más atroces de la historia chilena reciente. Pese a su fin, la vuelta a la democracia en muchos aspectos sociales, políticos y jurídicos hace pensar que el país aún se encuentra en una transición desde la dictadura a la anhelada democracia (Oteíza, 2009). ${ }^{1}$ Este régimen dejó a miles de muertos, desaparecidos, torturados, exonerados, exiliados y una larga lista de 40.000 víctimas y afectados indirectos (Oteíza \& Pinuer, 2016).

Para compensar los daños producidos por la violencia, el Estado Chileno decidió emplear un

Artigo recebido em: 30/12/2019

Aprovado em: 20/08/2020 modelo de Justicia transicional, el cual tiene de base un modelo de justicia restaurativa que buscar facilitar el trabajo con el daño y evitar así la vía legalista propia de los modelos de justicia retributiva (Cuenca, 2015). Esto se traduce en una serie de disposiciones legales, jurídicas y políticas en las que toma especial relevancia la reparación, entendida esta como toda acción administrativa o simbólica de restitución, indemnización, rehabilitación, construcción de memoria y otras tantas medidas de satisfacción que permitan el esclarecimiento de la verdad y el oportuno resarcimiento de las víctimas de los hechos violentos (Jelin, 2013; Lira, 2010; Passmore, 2016; Ríos, 2017). ${ }^{2}$

En este escenario de Justicia Transicional, Chile ha sido sindicado como un país ejemplar en lo concerniente a la reparación y sus políticas, no obstante, existen críticas en cuanto al bajo alcance de las políticas, la falta de protagonismo de las víctimas y el papel secundario de la memoria en las políticas públicas (Ruderer, 2010). Esto ha llevado a mostrar 
a Chile y su transición como un modelo exitoso, lo que ha generado una gran producción académica sobre las políticas de reparación y en especial sobre las formas en las que se ha hecho memoria ${ }^{3}$ como elemento central de la reparación.

Los estudios referentes a la transición chilena con relación a la memoria han tenido como temas recurrentes los Derechos Humanos (Collins, 2013), la Justicia transicional (Martínez \& Martínez, 2018), las leyes de reparación, el trauma psicosocial (Faúndez, Brackelaire \& Cornejo, 2013; Lira, 2010), las memorias de la dictadura (Fernández-Droguett, Jorquera-Álvarez \& Ramos-Basso, 2015; Piper-Shafir, 2017), la acción y participación de la sociedad civil (Garretón y Garretón, 2010; Huneeus, 2014) como también de los organismos estatales (Bernasconi-Ramírez, Mansilla-Santelices \& Suárez-Madariaga, 2019; García, 2006).

Otros estudios han puesto el énfasis en los hitos de la transición, resaltando el establecimiento de pactos que trajeron por consecuencia la impunidad en los ámbitos políticos-institucionales, económicos, militares y de justicia para los victimarios (Collins, 2013). Por último, cabría mencionar una serie de investigaciones que piensan la transición chilena desde ópticas diferentes como la perspectiva de género (Hiner, 2009) o la infancia (Castillo-Gallardo \& González-Celis, 2015; Haye et al., 2013).

Pese a ser un tema recurrente, no existen investigaciones previas que permitan afirmar con certeza cuál es el lugar de la memoria en estas políticas de reparación del Estado chileno, por lo que será objetivo del presente estudio, el analizar discursivamente, cómo se construye la noción de memoria en las políticas oficiales de reparación de la transición de Chile.

\section{Políticas de la reparación en Chile}

En Chile hay cierto consenso de que han existido una serie de dispositivos jurídico-políticos orientados a consolidar la memoria social en el país (Collins, Hite \& Joignant, 2013; del Valle, 2018). Así, pese a no ser explícito, es posible rastrear una serie de iniciativas ${ }^{4}$ de corte estatal en las que se norma la construcción del recuerdo; comisiones de verdad, perdones presidenciales, creación de instituciones y fechas conmemorativas, monumentos, mesas de diálogo, museos y otras orientadas por sobre todo a la reparación simbólica. A continuación, describiremos las vertientes oficiales de estas políticas, pues se encuentran expresadas en una serie de normas jurídicas que las regulan.

\section{Periodo 1990-2002: Informe Rettig}

Una de las primeras medidas de reparación del Estado chileno fue el Informe Rettig, publicado el año 1991 en un escenario "de consensos", el cual fue denominado como la "democracia de los acuerdos" (Geis, 1991; Rovira, 2007). Los resultados de esta Comisión Nacional de Verdad y Reconciliación (CNVR), ${ }^{5}$ se vieron truncados al día de ser publicados por el asesinato de Jaime Guzmán ${ }^{6}$ y por la fuerte resistencia de las Fuerzas Armadas, aún encabezadas por el exdictador Augusto Pinochet, quienes no reconocieron los hallazgos hechos por la comisión.

El gobierno chileno en pos de mantener la delicada democracia, señaló que trabajaría los temas de justicia, verdad y reparación "en la medida de lo posible" (Patricio Aylwin, 21 de mayo de 1990). Así, el Estado chileno dejó impune una serie de victimarios y dejó de lado a las víctimas llamadas "sobrevivientes", a las víctimas de la prisión política, del exilio y a los exonerados (Camacho, 2008). Pese a la validación social que recibió el informe, la opinión pública en un 69\% de los casos señaló que este era incompleto o no era capaz de entregar toda la verdad de lo sucedido (CEP, 7 de marzo de 1991).

Según autores, a partir del Informe Rettig el Estado comienza a promover una historia oficial, a la vez que instala las maneras en que estos hechos deben ser resarcidos y recordados (Rubio, 2013; Sepúlveda, 2014). En este marco, le siguen en el año 1992 y 1993, dos leyes que establecen los beneficios y las instituciones encargadas de velar por el cumplimiento de lo sugerido en el informe Rettig, a saber: la Ley 19.123 y la Ley 19.234. En estas, se crean pensiones, beneficios, el Programa de Reparación y Atención Integral de Salud (PRAIS) y la Corporación Nacional de Reparación y Reconciliación (CNRR).

Estas surgen en un momento histórico en el cual el exdictador aún mantenía un cargo de senador vitalicio autodesignado. De esta manera, la capacidad 
del Estado chileno de emitir políticas de reparación se vio coartada hasta el posterior encarcelamiento de Pinochet, su extradición y finalmente, la declaración de interdicción cursada a su favor con el fin de obtener su impunidad (Huneeus, 2014).

\section{Periodo 2003-2009: Informe Valech I y II}

En el año 2003 durante el mandato de Ricardo Lagos se emitió el Decreto Supremo 1.040 el cual permitió generar una nueva comisión de verdad llamada Comisión Nacional de Prisión Política y Tortura (CNPPT). Ante esta se presentaron los casos de 35.868 personas, siendo 27.255 calificadas como víctimas, proponiendo la Comisión, además, ciertos criterios de reparación específicos a las cualidades de estas. ${ }^{8}$ Estas disposiciones fueron materializadas mediante la Ley 19.992 de 2004, mientras que otras por medio de la Ley 19.980 del mismo año. A diferencia del Informe Rettig, este texto fue ampliamente apoyado por integrantes de las Fuerzas Armadas, de la Corte Suprema y recibió el apoyo de un $71 \%$ de la población en la primera encuesta CEP asociada (Sierra, 2005).

Pese a ser reconocido, se trata de una acción que difícilmente hubiera llegado a puerto si no fuera por la determinación de las víctimas, sus agrupaciones y familiares. Así, desde las asociaciones de DDHH, académicos y políticos, se señaló que los esfuerzos estatales eran insuficientes y que los gobernadores no eran capaces de guiar la reparación integral de la nación (Madariaga, 2005). Se habló de una imposición del olvido, puesto que los resultados del Informe dieron a conocer los hechos victimizantes, pero mantuvieron ocultos el nombre y la conducta de los torturadores y victimarios, limitando los alcances jurídicos y sociales del informe (Madariaga, 2005).

Se reclamó también por la parcelación de las víctimas, dada la entrega de bonificaciones más altas a familiares de "víctimas simbólicas". Estos familiares eran generalmente figuras de la Concertación (coalición de gobierno) y no, por ejemplo, figuras de los movimientos populares o de los movimientos sociales (Hiner, 2009). Así mismo, los mecanismos para determinar el número de víctimas fueron fuertemente criticados, dada las dificultades estructurales que significaba el presentarse a dar testimonio. Esto llevó al Estado chileno a emitir, bajo el gobierno de la presidenta Michelle Bachelet, dos nuevas disposiciones que complementarán lo ofrecido por el Informe Valech.

Así, en el año 2006 bajo la ley 20.134, se estableció un bono para exonerados políticos, hasta ahora no considerados por normas anteriores. Consiguiente a esta, se firmó en el año 2009 el Decreto Supremo 43, el cual mandató crear la Comisión Asesora Presidencial para la Calificación de Detenidos Desaparecidos, Ejecutados Políticos y Víctimas de Prisión, Política y Tortura, o Valech II, la que permitió llegar al actual número de más de 40.000 afectados.

Posteriormente se publicó la Ley 20.405 en 2009, la cual mandata la creación del Instituto de Derechos Humanos y del Premio Nacional de los Derechos Humanos. Por estos mismos ańos cabe mencionar, el diseño y construcción del Museo de la Memoria, monumento que fue oficializado por Michelle Bachelet en su cuenta pública de 2007 pero que se inauguró en 2010. ${ }^{9}$ Por último, en 2016, en el segundo gobierno de Bachelet, emerge la Ley 20.885 que crea la Subsecretaria de Derechos Humanos y el Plan Nacional del mismo tema para los años 2018-2021. Todos los informes, decretos y leyes antes mencionados se encuentran resumidos en la Tabla 1.

\section{Método}

Se realizó un análisis del discursivo de las leyes de reparación concernientes a la construcción de memoria. Se entendió el discurso como "un conjunto de prácticas lingüisticas que mantienen y promueven ciertas relaciones sociales" (Ińiguez-Rueda \& Antaki, 1994, p. 64). Consideramos que las leyes norman espacios y marcos regulatorios de interacción social que, como señalan Ligueño, Palacios \& Sandoval (2018), son susceptibles de ser analizadas y comprendidas en cuanto a imperativo que se quiere transmitir puesto que se considera que el lenguaje es capaz de visibilizar los sentidos en torno a una realidad social (Fairclough, 2003; Vázquez, 2001). Así, la ley se expresa utilizando un formato impersonal que a la vez busca ser un acto de habla directo, capaz de señalar aquello que se permite y aquello que no, haciendo explícito el objetivo que busca prescribir (Peńa-Ochoa, 2019). 
Tabla 1.

Leyes y Decretos de Chile de Reparación

\begin{tabular}{|c|c|c|}
\hline Norma jurídica & Ańo & Objetos de Ley \\
\hline Decreto Supremo No 355 & \multirow{2}{*}{1990} & \multirow{2}{*}{ Creación de la Comisión de Verdad y Reconciliación (1991). } \\
\hline "Comisión Rettig" & & \\
\hline \multirow{2}{*}{ Ley 19.123} & \multirow{2}{*}{1992} & Creación de la Corporación Nacional de Reparación y Reconciliación (1992). \\
\hline & & Se establece Pensión de Reparación (1992). \\
\hline Ley 19.234 & 1993 & Establece beneficios previsionales para Exonerados Políticos (1993). \\
\hline Decreto Supremo $\mathrm{N}^{\circ} 1.005$ & 1997 & Creación del Programa de Derechos Humanos (2009) \\
\hline Decreto Supremo $N^{\circ} 1.040$ & \multirow{2}{*}{2003} & \multirow{2}{*}{ Creación de la Comisión de Prisión Política y Tortura (2003). } \\
\hline "Comisión Valech" & & \\
\hline \multirow{2}{*}{ Ley 19.980} & \multirow[b]{2}{*}{2004} & Se amplía los términos de la Pensión de Reparación establecida en la Ley 19.123 \\
\hline & & $\frac{(2004) .}{\text { Creación del Programa PRAIS (1991).12 }}$ \\
\hline Ley 19.992 & 2004 & Establece la Pensión de Reparación de los beneficiarios Valech (2004). \\
\hline Ley 20.134 & 2006 & $\begin{array}{c}\text { Establece un Bono extraordinario para ex trabajadores del sector privado } \\
\text { Exonerados por motivos políticos }(2006)\end{array}$ \\
\hline Decreto Supremo No 43 & \multirow{2}{*}{-2009} & Creación de la Comisión Asesora Presidencial para la Calificación de Detenidos \\
\hline "Comisión Valech II" & & Desaparecidos, Ejecutados Políticos y Víctimas de Prisión, Política y Tortura (2009) \\
\hline \multirow{2}{*}{ Ley 20.405} & \multirow{2}{*}{2009} & Creación del Instituto de Derechos Humanos (2010). \\
\hline & & Creación del Premio Nacional de los Derechos Humanos (2011). \\
\hline \multirow{2}{*}{ Ley 20.885} & \multirow{2}{*}{2016} & Creación de la Subsecretaria de Derechos Humanos (2016) \\
\hline & & Creación de el Plan Nacional de Derechos Humanos (2018-2021) ${ }^{13}$ \\
\hline
\end{tabular}

Fuente: Elaboración propia.

Tabla 2.

\section{Muestra del Estudio}

\begin{tabular}{lc}
\hline \multicolumn{1}{c}{ Norma jurídica } & Ańo \\
\hline Decreto Supremo No 355 “Comisión Rettig” & 1990 \\
\hline Ley 19.123 & 1992 \\
\hline $\begin{array}{l}\text { Decreto Supremo No } 1.005 \text { “Programa de } \\
\text { Derechos Humanos" }\end{array}$ & 1997 \\
\hline Decreto Supremo No 1.040 “Comisión Valech” & 2003 \\
\hline Ley 19.980 & 2004 \\
\hline Ley 19.992 & 2004 \\
\hline Decreto Supremo No 43 “Comisión Valech II” & 2009 \\
\hline Ley 20.405 & 2009 \\
\hline Ley 20.885 & 2016 \\
\hline
\end{tabular}

Fuente: Elaboración propia.

\section{Muestra}

Para obtener la presente muestra se utilizó la técnica de recopilación documental (Montero \& Hochman, 2005). Se realizó una búsqueda de leyes, decretos y comisiones referentes a las políticas de la reparación en Chile que se enmarcan dentro del marco de la Justicia transicional y que concordaron con los siguientes criterios: 1) haber sido elaboradas a partir de 1990 y a raíz de los hechos violentos acontecidos en Dictadura, ${ }^{10}$ 2) tener una relación explícita con el recuerdo o la memoria en términos de reparación, 3) que, en caso de no cumplir con el punto dos, traten temas estrechamente ligados a la memoria social como la conmemoración a través de fechas y lugares, la noción de víctimas, el archivo de los testimonios, entre otros.

Cumplieron con estos criterios un total de tres comisiones de verdad, cuatro decretos supremos y cinco leyes que fueron promulgadas entre los años 1990 y 2016 (ver Tabla 2). Fueron obtenidas a través de la página LeyChile.cl y por medio de la página de la Biblioteca Nacional del Congreso.

\section{Procedimiento de análisis}

Se procedió siguiendo las indicaciones de Potter y Wetherell (1994), respecto de los repertorios 
interpretativos, entendidos estos como sistemas de términos utilizados con frecuencia para caracterizar y valorar ciertas acciones, relaciones, sucesos y fenómenos (Potter y Wetherell, 1987). Teniendo por primer objetivo generar las unidades discursivas en los textos (párrafos). Una vez delimitado el corpus textual, se procedió a codificar utilizando la herramienta Atlas. Ti en su versión 7.1. Para esto se realizó una lectura general acompañada de una selección de aquellas unidades consideradas como útiles. Con esto se simplificaron los textos y se agregaron en funciones prácticas del discurso.

Por último, en la fase del análisis propiamente tal, se buscó identificar la variabilidad y consistencias de los discursos, las funciones, ideas implícitas, patrones y discontinuidades, en pos de distinguir ciertos repertorios dominantes en el texto (Potter $\&$ Wetherell, 1994). Para esto, se tuvo como guía dos preguntas: ¿Cómo se construye el discurso sobre la memoria en las normas y comisiones de la verdad en Chile? y ¿cómo varía en función la construcción de este discurso sobre la memoria?

Para evitar posibles atajos y sesgos en el análisis, se tuvo en consideración elementos provenientes de estudios anteriores que suman rigurosidad a los análisis discursivos (Antaki, Billig \& Potter, 2003; Peña-Ocha, 2019) A partir de estos elementos, preguntas y del proceso de análisis subyacente, se construyeron los repertorios interpretativos que sirven de títulos en los resultados.

\section{Resultados}

La memoria en las políticas de reparación de Chile es entendida con ciertas particularidades discursivas lo que indicaría su variabilidad y su capacidad de construir realidades a partir de su posibilidad enunciativa. Esto es posible de ser rastreado a través de cuatro repertorios interpretativos en los que se ve cómo la memoria es construida, a saber, son: la reparación como verdad oficial, la recuperación de la dignidad humana y la dosificación de la memoria, las instituciones; el archivo; y la conmemoración.

\section{Repertorio reparación como verdad oficial, la recuperación de la dignidad humana y la dosificación de la memoria}

Uno de los puntos sobre los que se erigen las políticas de la reparación es el esclarecer la verdad sobre las violaciones a los DDHH y recuperar la dignidad perdida durante la dictadura. Esto aparece por primera vez en el Decreto supremo 355 de 1990, el cual dictamina la creación de la CNVR:

Núm. 355.- Considerando:

10.- Que la conciencia moral de la Nación requiere el esclarecimiento de la verdad sobre las graves violaciones a los derechos humanos cometidas en el país entre el 11 de septiembre de 1973 y el 11 de marzo de 1990;

$2^{\circ}$.- Que sólo sobre la base de la verdad será posible satisfacer las exigencias elementales de la justicia y crear las condiciones indispensables para alcanzar una efectiva reconciliación nacional;

$3^{\circ}$.- Que sólo el conocimiento de la verdad rehabilitará en el concepto público la dignidad de las víctimas, facilitará a sus familiares y deudos la posibilidad de honrarlas como corresponde y permitirá reparar en alguna medida el daño causado; [...]

8o.- Que el informe en conciencia de personas de reconocido prestigio y autoridad moral en el país, que reciban, recojan y analicen todos los antecedentes que se les proporcionen o puedan obtener sobre las más graves violaciones a los derechos humanos, permitirá a la opinión nacional formarse un concepto racional y fundado sobre lo ocurrido y proporcionará a los Poderes del Estado elementos que les permitan o faciliten la adopción de las decisiones que a cada cual correspondan. (Decreto 355, 1990, p.1-2)

El decreto refiere inicialmente a la conciencia moral de la nación como algo que requiere ser 
esclarecido con la verdad, siendo esta necesaria para cubrir las necesidades judiciales y de reparación del país. En especial, en el punto 3 y 8, se destaca la importancia de conocer esta verdad de manera racional y fundada, con el fin de rehabilitar en público la dignidad humana "perdida" por las víctimas de la Dictadura. Así, la verdad es el componente principal de la reparación y esta verdad hace referencia a modo de implicatura a la memoria, o en otras palabras el término de verdad es equiparable al de memoria en cuanto a que, cuando se emplea la noción de verdad, se está haciendo referencia implícita sobre el qué y el cómo se debe construir del pasado.

Por tanto, la verdad se convierte en un elemento para la institucionalización del recuerdo y se establece una teleología de la verdad/memoria, en la que, en primera instancia, el recuperar el pasado servirá para hacer un acto de contrición sobre la conciencia moral machacada, que luego servirá para recuperar la dignidad de las victimas y finalmente será efectiva para la reconciliación nacional lo que permitirá crear un concepto racional y fundado sobre lo ocurrido que permita adoptar decisiones sobre el futuro. Posteriormente, en el Informe Rettig (1991), se establece a la verdad como un elemento prioritario para construir el pasado y reparar a las víctimas:

El establecimiento de la Verdad aparece a la vez como una medida de prevención en sí misma y como el supuesto básico de cualquiera otra medida de prevención que en definitiva se adopte.

La Verdad, para que cumpla su función preventiva, debe reunir ciertos requisitos mínimos, a saber, ser imparcial, completa y objetiva, de manera de formar convicción en la conciencia nacional acerca de cómo ocurrieron los hechos y de cómo se afectó indebidamente la honra y la dignidad de las víctimas.

Se recuerda al efecto que el decreto que crea la Comisión Verdad y Reconciliación señala como propósito central de su misión "contribuir al esclarecimiento global de la verdad sobre las más graves violaciones a los Derechos Humanos cometidas en los últimos años" y que para cumplir tal propósito se estimó oportuno reunir el máximo de antecedentes de cada uno de los alrededor de 3.500 casos que le fueron denunciados, escuchando, en cuanto fue factible, a los familiares de cada una de las víctimas y a los testigos que ellos o las instituciones denunciantes presentaron.

Esta Comisión confía en que la Verdad así obtenida sirva en sí misma al propósito de prevención que se pretende alcanzar. (Informe Rettig, 1991, p.1297)

La verdad oficializada como forma objetiva de construir el pasado de la Dictadura, se vislumbra en el establecimiento de fechas, la tipología de las víctimas, el número de casos analizados, 3.500, la necesidad de mencionar que esta recuperación del pasado ha sido imparcial, completa y objetiva y, en que el pasado construido servirá para formar convicción en la conciencia nacional acerca de cómo ocurrieron los hechos y de cómo se afectó indebidamente la honra y la dignidad de las víctimas. Así se crea un pasado univoco, el cual las personas deban conocer y el cual debe permanecer en la conciencia nacional para que las atrocidades del pasado no se repitan.

La construcción de la memoria de la Dictadura reaparece 12 años después, con la creación de la CNPPT (2003), pues presuntamente no toda la verdad fue dicha ni toda la dignidad estaba recuperada. Esta nace como un esfuerzo que busca completar la memoria establecida por la CNVR en el Informe Rettig (1991). Al respecto el Decreto 1.040 indica:

Que, muchas de esas personas no han sido hasta la fecha reconocidas en su carácter de víctimas de la represión, ni han recibido reparación alguna por parte del Estado;

Que, sólo en la medida que se conozca en forma completa la verdad acerca de las violaciones de derechos humanos en Chile, se reconozca a sus víctimas y se repare el injusto mal causado, el país podrá avanzar en forma efectiva por el camino de la reconciliación y el reencuentro; 
Que, es una obligación del presidente de la República, encargado del Gobierno y la administración del Estado, promover el bien común de la sociedad y hacer todo cuanto su autoridad permita para contribuir al más pronto y efectivo esclarecimiento de toda la verdad y a la reconciliación de la Nación;

Que, la experiencia de la Comisión Nacional de Verdad y Reconciliación y de la denominada Mesa de Diálogo demuestran que es posible alcanzar crecientes grados de verdad, especialmente cuando la recopilación y sistematización de los antecedentes del caso es entregada a personas de reconocido prestigio y autoridad moral del país. (Decreto 1.040, 2003, p.1)

Al emitir este Decreto supremo, el Estado chileno reconoce que la memoria oficializada hasta ese entonces resulta insuficiente para lograr la reparación de aquellas víctimas que no han sido hasta la fecha reconocidas. Así, el Estado, crea una nueva Comisión para avanzar en los crecientes grados de verdad sobre los hechos violentos ocurridos en la Dictadura y con el fin de lograr la reconciliación, el reencuentro y el bien común de la sociedad. Este decreto construye la idea que la memoria como verdad oficial ha sido dosificada mediante grados de verdad, en cuanto a que es posible avanzar en los grados de veracidad dado que no todo lo sucedido está dicho.

La dosificación se puede rastrear, en un primer grado, en que se estableció como verdad que durante la Dictadura ocurrieron graves violaciones a los Derechos Humanos; en segundo grado, tal dosificación se observa en el reconocimiento de la prisión política y la tortura como violaciones a los DDHH que sucedieron; y en un tercer grado, en el reconocimiento de la ejecución política y la desaparición forzada. Esto se evidencia en los decretos 355 de 1990, 1040 de 2003, y el 43 de 2010, los cuales discursivamente se diferencian en la forma de nombrar los hechos cometidos
Artículo primero:

Créase una Comisión Nacional de Verdad y Reconciliación que tendrá como objeto contribuir al esclarecimiento global de la verdad sobre las más graves violaciones a los derechos humanos cometidas en los últimos años, sea en el país o en el extranjero, si estas últimas tienen relación con el Estado de Chile o con la vida política nacional, con el fin de colaborar a la reconciliación de todos los chilenos y sin perjuicio de los procedimientos judiciales a que puedan dar lugar tales hechos. (Decreto Supremo 355, 1990, p.2)

\section{Artículo Primero:}

Créase, como un órgano asesor del presidente de la República, una Comisión Nacional sobre Presión Política y Tortura, en adelante La Comisión, que tendrá por objeto exclusivo determinar, de acuerdo a los antecedentes que se presenten, quiénes son las personas que sufrieron privación de libertad y torturas por razones políticas, por actos de agentes del Estado o de personas a su servicio, en el período comprendido entre el 11 de septiembre de 1973 y el 10 de marzo de 1990. (Decreto Supremo 1.040, 2003, p.1-2)

Artículo $1^{\circ}$. -

Créase, como un órgano asesor del presidente de la República, una Comisión Asesora para la calificación de Detenidos Desaparecidos, Ejecutados Políticos y Víctimas de Prisión Política y Tortura, entre el 11 de septiembre de 1973 y el 10 de marzo de 1990, en adelante "la Comisión". (Decreto 43, 2010, p.1)

El Decreto Supremo 355 de 1990 nomina lo ocurrido como: "las más graves violaciones a los derechos humanos", el 1.040 de 2003 incluye a aquellas "personas que sufrieron privación de libertad y torturas por razones politicas, por actos de agentes del Estado o de personas a su servicio", mientras que el decreto 43 de 2010 propone la creación de una Comisión para 
"Ia calificación de Detenidos Desaparecidos, Ejecutados Politicos y Victimas de Prisión Politica y Tortura".

La dosificación de la memoria y los grados de veracidad también son posibles de rastrear en los informes de las Comisiones de la Verdad. En el prólogo del Informe Valech I, se señala que para avanzar en los grados de verdad será necesario sumariar a las víctimas, teniendo ahora en consideración a aquellas que sufrieron tortura y/o privación de libertad. En el Informe Valech II se señala que, bajo la misma pretensión, se calificaron nuevos casos:

Decidí entonces crear una Comisión Nacional sobre Prisión Política y Tortura, que fuera capaz de determinar el universo de quienes sufrieron privación de libertad y torturas por razones políticas entre septiembre de 1973 y marzo de 1990.

He recibido el informe de dicha Comisión. La madurez de Chile requiere conocer aquella parte de la verdad que todavía permanecía oculta a los ojos de mucha gente. Su contenido se hará público y estará al alcance de todos los chilenos y de la comunidad internacional. (Informe Valech, 2004, p.8)

La Comisión inició sus funciones el 17 de febrero de 2010. Recibió 622 casos de detenidos desaparecidos y ejecutados políticos, que corresponden a casos de desapariciones forzadas y ejecuciones extrajudiciales por motivos políticos, y a casos de víctimas de violencia política, y 31.831 solicitudes de calificación de personas que declararon haber sido víctimas de prisión política y tortura. La ocurrencia de todas las solicitudes y casos anteriores fue fechada entre el 11 de septiembre de 1973 y el 10 de marzo de 1990. Asimismo, a la Comisión fueron presentados 224 casos correspondientes a situaciones ya calificadas por Comisiones anteriores por los mismos hechos declarados a esta Comisión, los cuales no ingresaron al proceso de calificación. (Informe Valech II, 2010, p.1)
$\mathrm{Al}$ establecer como elemento prioritario de la $\mathrm{verdad} /$ memoria el reconocer al universo de quienes sufrieron y el que esto sea conocido y esté al alcance de todos los chilenos y de la comunidad internacional, o, en otras palabras, alcanzar crecientes grados de verdad mediante la correcta y objetiva determinación del número de casos. Así, los Informes Valech I y II establecen nuevas memorias/verdades que todavía permanecia(n) oculta(s) a los ojos de mucha gente, memorias que deben ser oficializadas y objetivadas con el fin de cumplir la teleología planteada en el Decreto supremo 355 de 1990 y en el informe Rettig.

\section{Repertorio instituciones}

La memoria se institucionaliza por medio de entidades estatales que prescriben cómo se debe oficializar la verdad, cómo debe revindicar la dignidad moral nacional y reparar a las víctimas. La primera de estas instituciones es la CNVR que, como ya se mencionó, es dictaminada mediante el Decreto Supremo 355 de 1990. Posteriormente, en el informe Rettig emitido en 1991, se recomendó al Estado la creación de una corporación que se enfocase en los procesos de reparación individual y reconciliación nacional ya iniciados por la CNVR. En este contexto, y partir de la Ley 19.123 de 1992, se regula la CNRR, la que entraría en vigor desde la fecha hasta 1996. Según el artículo 2 de la citada ley, serán funciones de esta institución:

Artículo $2^{\circ}$. - Le corresponderá especialmente a la Corporación:

1.- Promover la reparación del daño moral de las víctimas a que se refiere el artículo 18 y otorgar la asistencia social y legal que requieran los familiares de éstas para acceder a los beneficios contemplados en esta ley.

2.- Promover y coadyuvar a las acciones tendientes a determinar el paradero y las circunstancias de la desaparición o muerte de las personas detenidas desaparecidas y de aquellas que no obstante existir reconocimiento legal de su deceso, sus restos no 
han ido ubicados. En el cumplimiento de este objetivo deberá recopilar, analizar y sistematizar toda información útil a este propósito. [...]

4.- Recopilar antecedentes y efectuar las indagaciones necesarias para dictaminar en aquellos casos que conoció la Comisión Nacional de Verdad y Reconciliación y en que no le fue posible formarse convicción respecto de la calidad de víctima de violaciones a los derechos humanos o de la violencia política del afectado o respecto de casos de la misma naturaleza, sobre los que no tuvo conocimiento oportuno o, habiéndolo tenido, no se pronunció sobre ellos por falta de antecedentes suficientes. [...]

6.- Formular proposiciones para la consolidación de una cultura de respecto de los derechos humanos en el país. (Ley 19.123, 1992, p.1)

Del texto se desprende que la memoria es entendida en esta institución como el pivote entre la construcción de la verdad y la reparación del daño moral de las víctimas. Así, se regulan una serie de disposiciones relacionadas con el cómo hacer memoria; se entrega asistencia social y legal, se promueven acciones para determinar el paradero y las circunstancias de la desaparición o muerte de las personas detenidas desaparecidas, se recopilan antecedentes y testimonios de personas que no fueron calificadas como víctimas por la CNVR, y se formulan medidas para la educación en memoria y derechos humanos.

En el año 1997 es creado por el Decreto Supremo 1.005 el Programa de Derechos Humanos, el cual surge de las recomendaciones tanto de la CNVR como de la CNRR. Aun así, esta institución no fue formalizada hasta la aparición del INDH en la Ley 20.405 de 2009, en la cual se oficializan sus funciones. Actualmente, este programa cuenta con un área de proyectos, memoriales y gestión institucional orientada a la realización de obras de reparación simbólica con el fin de preservar y fomentar la memoria de las víctimas.

Para el 2003, se emite el Decreto Supremo 1.040 el cual dictamina la creación de una nueva comisión de verdad: La CNPPT. En el artículo segundo del decreto se señala que corresponderá a la comisión proponer una serie de medidas tanto de relación austera como simbólica para las víctimas de prisión política y tortura (Decreto Supremo 1.040, 2003).

En el ańo 2007, la presidenta Bachelet, durante su cuenta pública, decidió comprometerse con la creación del INDH y de un museo nacional de la memoria:

Haremos realidad la creación del Instituto de Derechos Humanos y fundaremos el primer Museo Nacional de la Memoria. Finalmente, algo especial. La familia, los amigos de Carlos Lorca, Juan Maino, Víctor Díaz, las familias y camaradas de tantos miles que fueron detenidos y que no volvieron, conmemoraremos cada día 30 de agosto como el Día Nacional del Detenido Desaparecido. Un legado ético que mi generación dejará para la posterioridad. (Michelle Bachelet, 2007, p.36)

Pese a ser comprometido por la presidenta Bachelet, este instituto fue recomendado por la CNPPT (2004). Aun así, este no queda reglado hasta la ley 20.405 de 2009 donde se le propone como institución encargada de velar por la promoción de los derechos humanos en Chile. Esto lo podemos observar en el Artículo 2 de la mencionada ley:

Artículo $2^{\circ}$.- El Instituto tiene por objeto la promoción y protección de los derechos humanos de las personas que habiten en el territorio de Chile, establecidos en las normas constitucionales y legales; en los tratados internacionales suscritos y ratificados por Chile y que se encuentran vigentes, así como los emanados de los principios generales del derecho, reconocidos por la comunidad internacional. (Ley 20405, 2009, p.1)

En lo que respecta a la memoria el artículo 3 de la misma ley, señala una serie de funciones entre las que cabe destacar la creación de un informe anual sobre derechos humanos, que este incluya medidas y estrategias de acción, que aporte a procesos legales 
y judiciales, y que conserve el archivo y promueva la memoria histórica en Chile:

Artículo $3^{\circ}$. - Le corresponderá especialmente al Instituto: $[\ldots]$

6.- Custodiar y guardar en depósito los antecedentes reunidos por (las comisiones) [...]

En el cumplimiento de este objetivo, deberá recopilar, analizar y sistematizar toda información útil a este propósito; también podrá solicitar información acerca del funcionamiento de los mecanismos reparatorios e impulsar, coordinar y difundir acciones de orden cultural y simbólico destinados a complementar el respeto a los derechos humanos y a reivindicar a las víctimas y a preservar su memoria histórica.

Asimismo, solicitar, reunir y procesar el conjunto de la información existente en poder de entes públicos o privados, que diga relación con las violaciones a los derechos humanos o la violencia política a que se refiere el Informe de la Comisión Nacional de Verdad y Reconciliación, sin perjuicio de lo dispuesto en el inciso primero. (Ley 20.405, 2009, p.1-2).

Esta es la primera ley en la que se dictamina de manera explícita que una institución estatal debe velar por preservar la memoria histórica de lo acontecido durante la dictadura. Así, la memoria empieza a funcionar no solamente como un elemento para la reparación moral de las víctimas, sino que es incluida en un abanico más amplio de acciones de orden cultural y simbólico orientadas a complementar el respeto a los derechos humanos. Esto genera un desplazamiento discursivo, pasando de la verdad como foco central de la recuperación del pasado, a privilegiar el fomento de los derechos humanos para su construcción

En la misma ley 20.405 (2009) se sugiere la creación de una Comisión de la verdad que sea capaz de mejorar el sistema de calificación de víctimas de la Comisión Valech I: la Comisión Asesora para la calificación de Detenidos Desaparecidos, Ejecutados
Políticos y Víctimas de Prisión Política y Tortura. Esta, fue mandatada por la presidenta Bachelet en el año 2010, mediante el decreto supremo 43:

En esta Comisión se actualizan los objetivos permanentes de la acción del Estado desde 1990, los que han apuntado a establecer la verdad de lo sucedido, identificar y reconocer a las víctimas e implementar políticas de reparación. El Estado debe garantizar el acceso a la justicia y construir institucional, política y culturalmente garantías de no repetición. Esta Comisión tuvo como tarea principal la calificación de víctimas de las situaciones de violaciones de derechos humanos definidas en el mandato de cada una de las comisiones anteriores. Es, por tanto, continuadora de la Comisión Rettig, de la Corporación y de la Comisión Valech. (Informe Valech II, 2010, p. 52)

Esta nueva comisión y su respectivo informe actualizan la memoria consignada en los informes Rettig y Valech I, en cuanto al número y tipo de víctimas de la dictadura. El desplazamiento discursivo antes mencionado, desde la memoria como verdad oficial hacia la memoria como garante de los DDHH se hace aún más evidente con la promulgación de la ley 20.885 de 2016, en la que se crea la Subsecretaria de DDHH, la cual dentro de sus funciones tiene como objetivo la formulación y ejecución del Plan Nacional de Derechos Humanos. Al respecto de esto se señala en el artículo 14 de la misma ley el que:

Artículo 14 bis.- [...] El Plan Nacional se materializará en la elaboración de políticas que abordarán al menos especialmente las siguientes materias: a) La promoción de la investigación, sanción y reparación de los crímenes de lesa humanidad y genocidios, y crímenes y delitos de guerra, en especial, según correspondiere, aquellos comprendidos entre el 11 de septiembre de 1973 y el 10 de marzo de 1990 . b) La preservación de la memoria histórica de las violaciones a los derechos humanos. (Ley 20.885, 2016, p.5) 
En esta ley la memoria aparece de manera explícita como una política que es expresión material del Plan Nacional de Derechos Humanos. Esta política deberá estar orientada a la preservación de la memoria histórica con el fin de evitar la repetición de las graves violaciones a los DDHH.

\section{Repertorio Archivo}

Las normas en ocasiones entienden a la memoria como un archivo, que es la materialización de aquella verdad objetivada y que da la posibilidad de centralizar o reunir las diversas piezas que conformarían los hechos violentos acaecidos en Dictadura. Se puede rastrear el origen de esto en las recomendaciones del Informe Rettig de 1991, el cual señala la necesidad de disponer de un ente que centralice la información acumulada por la CNVR:

Centralización de la información acumulada por la comisión. Un tercer orden ${ }^{11}$ de materias está relacionada con las investigaciones que en el futuro deseen hacer académicos, estudiantes universitarios, organismos no gubernamentales, estudiosos nacionales y extranjeros, o simplemente el público en general, que desee conocer o profundizar en el conocimiento de lo ocurrido en Chile en relación con las violaciones de derechos humanos. Pareciera necesario disponer de un ente que centralice los archivos y antecedentes sobre los casos, y disponga de una biblioteca especializada en el tema, al que se pueda tener acceso en las condiciones que la ley regule. (Informe Rettig, 1991, p.1300)

Así, con esto se crea la necesidad de construir un archivo en el que se pueda almacenar el "conocimiento de lo ocurrido en Chile en relación con las violaciones de derechos humanos" (Informe Rettig, 1991, p.1300). Esta disposición archivística fue rápidamente integrada por la CNRR mediante la Ley 19.123 de 1991, en la cual una de las funciones de la Corporación es el recopilar y gestionar el archivo:
Artículo $2^{\circ}$.- Le corresponderá especialmente a la Corporación:

[...] 3.- Guardar en depósito los antecedentes reunidos tanto por la Comisión Nacional de Verdad y Reconciliación como por la Corporación Nacional de Reparación y Reconciliación y todos aquellos que, sobre casos y asuntos similares a los por ella tratados, se reúnan en el futuro.- Podrá asimismo, requerir, reunir y procesar el conjunto de la información existente en poder de entes públicos, así como solicitarla a entes privados, que diga relación con las violaciones a los derechos humanos o la violencia política a que se refiere el Informe de la Comisión Nacional de Verdad y Reconciliación. [...]

4.- Recopilar antecedentes y efectuar las indagaciones necesarias para dictaminar en aquellos casos que conoció la Comisión Nacional de Verdad y Reconciliación y en que no le fue posible formarse convicción respecto de la calidad de víctima de violaciones a los derechos humanos o de la violencia política del afectado o respecto de casos de la misma naturaleza, sobre los que no tuvo conocimiento oportuno o, habiéndolo tenido, no se pronunció sobre ellos por falta de antecedentes suficientes. (Ley 19.123, 1992, p.1-2)

Como se puede observar, este archivo refiere a aquellos casos y hechos que fueron reconocidos por la CNVR (1991), por lo que será fundamental entonces para la CNRR (1992), guardar en depósito aquellos documentos provenientes de diversos entes que tengan relación con el Informe Rettig, o recopilar, aquellos que permitan establecer potenciales casos de los cuales no (se) tuvo conocimiento oportuno o, habiéndolo tenido, no se pronunció sobre ellos. Tanto el Informe Rettig (1991), como la Ley 19.123 (1992) y otras normas como el Decreto Supremo 1.0402003 y Ley 20.405 de 2009, enfatizan la necesidad de asegurar la absoluta confidencialidad de la información contenida en el archivo, dejando su libre acceso apenas a los Tribunales de Justicia. Así, pese a que el Decreto Supremo 355 de 1990 y el Informe Rettig de 1991 versen la necesidad de poner a disposición todos los 
recursos que permitan a la opinión nacional formarse un concepto racionaly fundado sobre lo ocurrido, estos se encuentran limitados a los poderes estatales y judiciales. Esto se puede ver de manera más clara en el artículo 15 de la Ley 19.992 de 2004, en el cual se establece un periodo de 50 años de secreto para los antecedentes recopilados por el Ministerio del Interior y por las dos Comisiones de verdad.

Con la emergencia del Informe Valech (2004), este archivo no solo tiene carácter de confidencial, sino también el de ser parte del patrimonio de cultural de la nación por lo que cabe crear un ente que evite que sea sustraída o destruida. Esto es señalado en las recomendaciones de dicho informe:

Resguardo y confidencialidad de la información recibida. La información recopilada por la Comisión, a través de los testimonios de las personas, como a través de las indagaciones que ésta hizo para la calificación de ellos, es parte del patrimonio cultural de la nación y debe ser sometida a medidas de resguardo. Por ello se recomienda que, al terminar su actividad, el acervo documental reunido a lo largo de su vigencia sea entregado en su conjunto al Instituto Nacional de Derechos Humanos que se cree o, en su defecto, al organismo encargado por ley de la conservación del patrimonio documental de la nación chilena. Dicha entidad estatal conservadora deberá tomar las medidas de protección contra toda sustracción y destrucción. (Informe Valech, 2004, p.530)

El archivo estaría constituido por el conjunto de testimonios de aquellos casos determinados como verídicos por la CNPPT (2003). Esta función se fijaría finalmente en el artículo 3 de la Ley 20.405 de 2009, poniendo como objetivo del INDH el "custodiar y guardar en depósito los antecedentes reunidos por" la CNVR, la CNRR, el Programa de Derechos Humanos, la CNPPT, como también del trabajo resultante de la futura Comisión Presidencial Asesora para la Calificación de Detenidos Desaparecidos, Ejecutados Políticos y Víctimas de Prisión Política y Tortura (Valech II).

\section{Repertorio de conmemoración}

La memoria se convierte en acción simbólica al conmemorar el pasado por medio de la fijación de fechas, la creación de premios y fondos asociados a los DDHH y la designación de sitios de memoria.

\section{Fechas}

A la vuelta de la democracia se crearon cinco días de conmemoración, siendo uno de estos derogado más adelante. La primera de estas fechas surge de las recomendaciones del Informe Rettig y se regula en el Decreto 861 de 1990: El día de los derechos humanos, el cual se celebra "el 10 de diciembre de cada año" (Decreto 861, 1990, p.1). En 1998 se crea la Ley 19.588 , la cual mandata celebrar el Día de la Unidad Nacional a principio de septiembre, en una clara alusión al Golpe de Estado. Posteriormente, se crea la ley 19.793 de 2003 la cual tiene por objetivo único derogar esta conmemoración.

En 2006, a raíz del informe Valech I (2004), se emite el decreto 121, el cual dictamina la conmemoración de los detenidos desaparecidos cada día 30 de agosto, acogiendo la fecha internacional en la cual se conmemoraba a los detenidos desaparecidos:

\section{Considerando: [...]}

3) Que no obstante nuestra tradición democrática y libertaria, nuestro país no está exento de sucesos y períodos reñidos con los valores mencionados, como los ocurridos a partir del 11 de septiembre de 1973, que no solo nos enlutan, sino también nos demandan acciones de memoria y justicia para superarlos y evitar su repetición;

4) Que, en tal sentido, los gobiernos democráticos han impulsado diversas iniciativas tendientes a revelar con exactitud los hechos y acciones contrarias a los derechos humanos que tuvieron lugar en nuestro país, a reparar en la medida de lo posible a las víctimas y sus familiares, a crear conciencia y memoria sobre dichos sucesos y a 
fomentar y promover el respeto irrestricto de los valores y derechos que profesa nuestra nación; [...]

8) Que la institución de un día nacional en conmemoración de nuestros compatriotas detenidos desaparecidos es una medida que contribuye a la reparación y a la construcción de una memoria histórica común, para que nunca más se vuelva a practicar la desaparición forzada de personas en nuestro país ni en el mundo,

Decreto: Institúyese el día 30 de agosto como el Día Nacional del Detenido Desaparecido. (Decreto 121, 2006, p.1)

Las últimas dos fechas fueron decretadas en el gobierno de Bachelet. La primera, corresponde al día 26 de junio, Día internacional en apoyo a las víctimas de la tortura (Decreto 77, 2009), la segunda, al 30 de octubre destinada a la conmemoración de los ejecutados por motivos políticos durante la Dictadura (Decreto 119, 2010):

7. Que, el 26 de junio se conmemora en muchos países del mundo el Día Internacional en Apoyo a las Víctimas de la Tortura, fecha que fue proclamada por la Asamblea General de las Naciones Unidas el 12 de diciembre de 1997 con la esperanza de despertar la solidaridad hacia las víctimas de estas prácticas inhumanas y sus familiares, así como lograr apoyo a su tratamiento y rehabilitación.

Decreto: Artículo único. Institúyase en Chile el 26 de junio de cada año, como el Día Nacional contra la Tortura. (Decreto 77, 2009, p.1)

7. Que, durante muchos años el día 30 de octubre se ha conmemorado como el día nacional del ejecutado político.

8. Que, mediante carta de 1 de octubre de 2009, la Agrupación de Familiares de Ejecutados Políticos, ha solicitado la instauración del Día Nacional del Ejecutado Político.
Decreto: Artículo único. Institúyase en Chile el 30 de octubre de cada año, como el Día Nacional del Ejecutado Político. (Decreto 119, 2010, p.1)

Así, podemos observar que Chile ha seguido una lógica de la conmemoración fuertemente asociada a fechas celebradas internacionalmente y a la necesidad de responder a las demandas de acciones de memoria que le han interpuesto al Estado los familiares de las víctimas. Así, el cuándo debe recordarse queda fijado, sin establecer mecanismos claros del cómo, limitándose el accionar del Estado al acto simbólico de fijar un calendario.

\section{Premios, fondos nacionales y lugares}

Otra manera de conmemorar es la instauración de un Premio Nacional de Derechos Humanos y de la Paz el cual, pese a ser recomendado en el Informe Rettig (1991), no se oficializó hasta el 2009 con la ley 20.405:

Instauración de un Premio Nacional de Derechos Humanos y de la Paz de idéntica categoría a los demás premios nacionales, que se entregará a la institución o persona que tenga un comportamiento destacado en la promoción y defensa de los derechos humanos. (Informe Rettig, 1991, p.431)

Artículo 14.- Créase el Premio Nacional de los Derechos Humanos, con el propósito de cultivar una memoria histórica sana de la Nación chilena, a través de resaltar y valorar cada dos años una persona de nacionalidad chilena, hombre o mujer, que se haya distinguido en tal esfuerzo. (Ley 20405, 2009, p.6)

De manera similar el Informe Valech I (2004) sugirió la creación de tres fondos relacionados con los derechos humanos, uno para la investigación en matrería de derechos humanos, otro orientado a destacar creaciones literarias que permitan reconocer lo sucedido y un último, asociado a obras de arte que persigan los mismos fines antes mencionados: 
2. Creación de un fondo concursable permanente para proyectos de investigación en materias de respeto a los derechos humanos. 3. Creación de un fondo editorial para publicación de testimonios y obras literarias que permitan reconocer lo sucedido, y de otro fondo para otras obras de arte con la misma finalidad; ambos con una duración limitada en el tiempo. (Informe Valech, 2004, p.348).

Aquí es visible que el Estado, para cultivar una memoria histórica sana, fija normas en las que busca reconocer a aquellas personas que se haya(n) distinguido en la defensa de los derechos humanos o que puedan concursar por fondos. Así, este no se ocupa directamente de la acción conmemorativa, ya que su función es otorgar dinero para que la sociedad civil sea la encargada de conmemorar, la que, dados los criterios de selección, se ve reducida a unos pocos, lo que termina por elitizar el recuerdo.

Finalmente, respecto de los lugares y sitios de conmemoración, tanto el Informe Rettig (1991) como el Informe Valech I (2004) integraron entre sus sugerencias la creación de monumentos:

- Erigir un monumento recordatorio que individualice a todas las víctimas de derechos humanos y a los caídos de uno y otro lado;

- Construir un parque público en memoria de las víctimas y caídos, que sirva de lugar de conmemoración y enseñanza, a la vez que de recreación y de lugar de reafirmación de una cultura por la vida. (Rettig, 1991, p.1255)

Declaración de los principales centros de tortura como monumentos nacionales y la creación de memoriales y sitios recordatorios de las víctimas de violaciones a los derechos humanos y violencia política. Para ello se propone evaluar lugares con las características de ser identificados por las víctimas como representativos de lo ocurrido, ubicados en diferentes regiones y que puedan servir al propósito de reconocimiento de lo sucedido y compromiso con el respeto de la dignidad de las personas. (Informe Valech, 2004, p.528)

Estos, según el artículo octavo de la Ley 19.980 de 2004, quedarán bajo responsabilidad de toda persona o entidad sin fines de lucro interesada en generar convenios de financiamiento con el Ministerio del Interior:

Artículo octavo.- En el presupuesto del Ministerio del Interior se consultarán los recursos que éste deberá destinar al financiamiento de convenios que celebre con organismos, entidades y personas jurídicas, todas sin fines de lucro, para la creación y mantención de memoriales y sitios históricos recordatorios de las víctimas a que se refiere el artículo 18 de la ley No 19.123.(Ley 19980, 2004, p.2).

En síntesis, lo que se encuentra en Chile respecto de la conmemoración en lugares son sugerencias emitidas por los informes, lo que no es vinculante en términos legales, por lo que la creación de estos monumentos recae en la sociedad civil.

\section{Conclusiones}

Las normas establecidas por el Estado chileno durante la transición denotan un interés en resarcir la violación a los DDHH cometida durante la Dictadura. Dentro de este marco normativo y jurídico, la reparación de las víctimas como fin máximo ha generado marcos sociales en los que es posible dar un sentido univoco y clausurado del pasado.

Las normas han propuesto una teleología de la memoria que se ancla en recuperar la verdad para poder reparar a las víctimas y a la dignidad nacional, para lograr una reconciliación nacional y el respeto a los DDHH y que, finalmente, se constituye como el acto más importante de reparación de las víctimas, al ser la difusión de la verdad construida en los Informes considerada como una medida de reparación en sí. Esta memoria/verdad permite que se termine el silencio y se destierre el olvido, lo que trae por consecuencia el lograr revindicar la dignidad de las víctimas. 
De tal modo, la reparación propuesta por el Estado se da mediante la formulación de normas que han dosificado, en crecientes grados de verdad, la memoria de lo ocurrido (Bernasconi-Ramírez, Mansilla-Santelices \& Suárez-Madariaga, 2019; Oteíza, 2009). Así, la teleología propuesta se completa en cuanto a que recuperar el pasado servirá para resarcir la moral dañada, lo que luego permitirá recuperar la dignidad de las víctimas, para finalmente hacer efectiva la reconciliación nacional y crear un pasado en pequeñas dosis, el cual es objetivo, racional y fundado en pos de tomar decisiones para el futuro.

Esa misma dosificación generó lo que se podría llamar una elitización del recuerdo, en cuanto que en primera instancia no toda la verdad fue dicha y que sólo ciertas personas tendrían el acceso a ella (Collins, Hite \& Joignant, 2013; Hite \& Collins, 2009). Así, para la sociedad civil resta conmemorar el calendario de fechas ofrecidas por el Estado, luchar por conseguir el reconocimiento de sus monumentos $\mathrm{y}$ ver los mecanismos por los cuales sortear los filtros impuestos para los Premios y Fondos.

Por último y con base en los resultados anteriormente expuestos, se plantea la hipótesis de que la gestión de la memoria por medio de las normas chilenas se asemejaría a una esteganografía del pasado (Eco \& Migiel, 1988), es decir a un mensaje oculto a la vista de todos, pero solo aquellas personas que conozcan todas las claves y sepan interpretarlas, podrán descifrar el mensaje de la memoria de la dictadura. Esta hipótesis se funda en que, para descubrir el mensaje oculto de la memoria establecida en las leyes se deben seguir una serie de pasos: primero, se debe recuperar aquello que se constituye como la verdad oficial sobre los hechos violentos; luego, es necesario que se creen instituciones que administren el pasado; así mismo, una de estas debe encargarse de almacenar los relatos y testimonios de lo acontecido; para finalmente, levantar entes estatales que se encarguen de conmemorar a las víctimas.

Por último, otro aspecto vinculado con esta hipótesis tiene que ver con el acceso a la verdad en pequeñas dosis a lo largo del tiempo, puesto que sólo quienes puedan unir este rompecabezas de memoria dosificada podrán acceder a la imagen global del pasado. Esto implica una elitización de la memoria, pues la posibilidad de descifrar el código de la esteganografía será un privilegio de solo ciertas personas calificadas para ello. Así, si se suman todas estas pistas, las personas indicadas podrán descifrar la esteganografía que son las políticas oficiales de la memoria de la Dictadura en Chile.

\section{Agradecimientos}

La presente investigación fue financiada por el proyecto FONDECYT Postdoctorado 3170814, 2017-2020.

\section{Notas}

1 Para tener un estado del arte actualizado respecto de la transición y los derechos humanos en Chile, se sugiere visitar el "Informe Anual de Derechos Humanos" en su versión 2018 y 2019, ambos elaborados por el Instituto Nacional de Derechos Humanos: https://bibliotecadigital. indh.cl

2 La justicia transicional como marco para la superación de la violencia, genera escenarios para "esclarecer la verdad y definir las formas de reparación" (Cuenca, 2015, p.56), por medio de la recuperación de las memorias de la violencia y de la violación a los derechos humanos (Rettberg \& Ugarriza, 2016). En este sentido, la recuperación de las memorias de las víctimas es indispensable para la transición y para la reparación. A pesar de esta vinculación entre la recuperación de la memoria, la verdad y la justicia, esta triple asociación no es del todo clara ni explícita en la Justicia Transicional (Dulitzky, 2017).

3 Esta entendida como una práctica socialmente construida de carácter procesual y política, en constante elaboración y nunca libre de múltiples interpretaciones (Vázquez, 2001; Lifschitz, 2014).

4 La sociedad civil ha generado acciones de memoria no oficiales, las cuales han tenido importancia, por nombrar algunas: Red de Sitios de Memoria, Día del Joven Combatiente o la celebración del 11 de septiembre en el Estadio Nacional.

5 Es la primera Comisión de Verdad que reconoce el "terrorismo de Estado", datándose un total de 2.996 casos considerados víctimas, aunque desconociéndose a los actores de estos actos en un $64 \%$ de los registros reportados (Bernasconi-Ramírez, Mansilla-Santelices \& Suárez-Madariaga, 2019). 
6 Guzmán fue un abogado que ejerció como asesor en temas jurídicos y legales en dictadura y participó en la elaboración de la Constitución de 1980. Es fundador del partido Unión Demócrata Independiente asociado a la Dictadura.

7 Casos que, a pesar de haber sufrido todas las represiones como la detención clandestina, las torturas y las violaciones, seguían aún con vida una vez terminada la Dictadura.

8 Finalmente, 28.459 personas fueron calificadas como víctimas y se estimó que aproximadamente 100.00 fueron víctimas de tortura, cifra más alta en relación con el número de habitantes de las Dictaduras del Cono Sur (Bernasconi-Ramírez, Mansilla-Santelices \& Suárez-Madariaga, 2019).

9 Este Museo, tal como otros lugares de memoria en Chile, surge a través de las gestiones de un gobierno, pero es producto de una alianza público-privada. Esto quiere decir que las colecciones y piezas de esta son privadas pero los recursos provienen del Estado, la administración recae en la Fundación Museo de la Memoria y los Derechos Humanos, aunque la edificación sea pública. Esto hace que los lugares corran con destinos inciertos; por ejemplo, el Monumento a las Mujeres Víctimas de la Represión Política también tuvo cierto soporte estatal, pero al no tener el mismo respaldo que un ente como el Museo de la Memoria, termina deteriorándose y quedando en el olvido. Otro ejemplo es la Clínica Santa Lucía, edificio que pertenece al Estado y al Consejo Nacional de Monumentos por medio del Decreto número 136 de 2016, pero que sobrevive gracias a las gestiones y recursos de organizaciones ciudadanas de memoria. Esto en algunos casos reduce el ejercicio de memoria no solo al binomio estado-interesados, sino que enfrenta a las organizaciones civiles a una vorágine por los recursos y la subsistencia.

10 Adicionalmente, para la identificación de estas normas, se tuvo como referencia diferentes fuentes oficiales vinculadas a la reparación. Por ejemplo, la nómina de Leyes de Reparación del Instituto de Previsión Social: https://www.ips.gob.cl/servlet/internet/inicio/beneficiosy-pensiones/leyes-de-reparacion. Se revisó también el Capitulo 6 del "Informe Anual 2017: Situación de los Derechos Humanos en Chile" elaborado por el Instituto Nacional de Derechos Humanos: https:// bibliotecadigital.indh.cl/handle/123456789/1072.

11 El primer orden hace referencia a colaboración en la búsqueda de las víctimas, el segundo a la recopilación de antecedentes y calificación de los mismos.

12 Su creación se remonta a 1991, siendo una de las primeras medidas de reparación. Se incluye el PRAIS en el listado pues la construcción de memoria se hace de manera práctica en la cotidianidad con los usuarios y no desde la ley.

13 Bajo este nuevo Plan los monumentos y lugares de memoria podrán optar a una política de financiamiento, conservación y monitoreo estatal. Este no se ha materializado producto de las dificultades de implementación que trajo consigo el cambio de gobierno de izquierda (Michelle Bachelet) a derecha (Sebastián Piñera) y las diversas crisis sociales y sanitarias. En este marco, existen instituciones privadas que reciben aportes estatales como Villa Grimaldi pero también iniciativas ciudadanas que no cuentan con ningún tipo de respaldo. Su única opción es acogerse a la Ley Nacional de Monumento Históricos, y tras la deliberación de un comité quedar consignados como un lugar de patrimonio nacional, sin que esto signifique necesariamente mantención o un aporte económico.

\section{BIBLIOGRAFÍA}

ANTAKI, Charles; BILLIG, Michael; POTTER, Jonathan. (2003), "El Análisis del discurso implica analizar: Crítica de seis atajos analíticos". Athenea Digital. Revista de pensamiento e investigación social, 1, 3: 14-35.

BERNASCONI-RAMÍREZ, Oriana; MANSILLASANTELICES, Daniela \& SUÁREZ-MADARIAGA, Rodrigo. (2019), "Las comisiones de la verdad en la batalla de la memoria: usos y efectos disputados de la verdad extrajudicial en Chile". Colombia Internacional, 97: 27-55.

CAMACHO, Fernando. (2008), "Memorias enfrentadas: las reacciones a los informes Nunca Más de Argentina y Chile". Persona y sociedad, 22, 2: 67-99.

CASTILLO-GALLARDO, Patricia \& GONZÁLEZCELIS Alejandra. (2015), "Infancia, dictadura y resistencia: hijos e hijas de la izquierda chilena (1973-1989)". Revista Latinoamericana de Ciencias Sociales, Niñez y Juventud, 13, 2: 907-921.

COLLINS, Cath. (2013), "Chile a más de dos décadas de justicia de transición”. Politica, Revista de Ciencia Politica, 51, 2: 79-113.

COLLINS, Cath; HITE, Katherine \& JOIGNANT, Alfredo. (2013), "Introducción", in C. Collins, K. Hite \& A. Joignant (eds.), Las Políticas de la Memoria en Chile: Desde Pinochet a Bachelet, 
Santiago, Ediciones Universidad Diego Portales, 25-54.

CUENCA, Ronald. (2015), "El concepto de justicia transicional a nivel internacional y sus diferencias y semejanzas con otros modelos de justicia”. Verbum, 10, 10: 49-62.

DECRETO Nº 861 declara como Día nacional de los Derechos Humanos el 10 de diciembre de cada año. Diario Oficial de la República de Chile, Santiago, Chile, 14 de diciembre de 1990.

DECRETO No 121 instituye Día nacional del Detenido desaparecido. Diario Oficial de la República de Chile, Santiago, Chile, 30 de agosto de 2006.

DECRETO N 77 establece Día nacional contra la Tortura. Diario Oficial de la República de Chile, Santiago, Chile, 10 de septiembre de 2009.

DECRETO N 119 establece Día nacional del Ejecutado político. Diario Oficial de la República de Chile, Santiago, Chile, 5 de enero de 2010.

DECRETO N 136 declara Monumento Nacional en la categoría de Monumento Histórico al "Ex Centro de Detención Clínica Santa Lucía”. Diario Oficial de la República de Chile, Santiago, Chile, 19 de mayo de 2016.

DECRETO SUPREMO N 355 crea Comisión de Verdad y Reconciliación. Diario Oficial de la República de Chile, Santiago, Chile, 25 de abril de 1990.

DECRETO SUPREMO N 1005. Diario Oficial de la República de Chile, Santiago, Chile, 9 de junio de 1997.

DECRETO SUPREMO N 1040 crea Comisión Nacional sobre Prisión Política y Tortura, para el esclarecimiento de la verdad acerca de las violaciones de Derechos Humanos en Chile. Diario Oficial de la República de Chile, Santiago, Chile, 26 de septiembre de 2003.

DECRETO SUPREMO N 43 establece Comisión Asesora para la calificación de Detenidos Desaparecidos, Ejecutados Políticos y Víctimas de Prisión Política y Tortura entre el 11 de septiembre de 1973 y el 10 de marzo de 1990. Diario Oficial de la República de Chile, Santiago, Chile, 27 de enero de 2010.
DEL VALLE, Nicolás. (2018), "Memorias de la (pos) dictadura: prácticas, fechas y sitios de memoria en el Chile reciente". Revista Mexicana de Ciencias Politicas y Sociales, 63, 232: 301-322.

DULITZKY, Ariel. (2017), "Derechos humanos en Latinoamérica y el Sistema interamericano: Modelos para (des)armar”. Querétaro: Instituto de Estudios Constitucionales del Estado de Querétaro.

ECO, Umberto \& MIGIEL, Marilyn. (1988), "An Ars Oblivionalis? Forget It!”. PMLA, 103, 3: 254-261. doi:10.2307/462374

FAIRCLOUGH, Norman. (2003), Analysing discourse: Textual analysis for social research, New York, Psychology Press.

FAÚNDEZ, Ximena; BRACKELAIRE, JeanLuc \& CORNEJO, Marcela. (2013), "Transgeneracionalidad del trauma psicosocial: imágenes de la detención de presos políticos de la dictadura militar chilena reconstruidas por los nietos". Psykhe (Santiago), 22, 2: 83-95.

FERNÁNDEZ-DROGUETT, Roberto; JORQUERAÁLVAREZ, Tamara \& RAMOS-BASSO, Javiera. (2015), "Violencias y resistencias desde una Producción Narrativa con militantes del Chile postdictatorial”. Athenea Digital, Revista de pensamiento e investigación social, 15, 4: 223-251.

GARCÍA, Carolina. (2006), "El peso de la memoria en los inicios de la transición a la democracia en Chile (1987-1988)". Historia (Santiago), 39, 2: 431-475.

GARRETÓN, Manuel \& GARRETÓN, Roberto. (2010), "La democracia incompleta en Chile: La realidad tras los rankings internacionales". Revista de Ciencia Politica (Santiago), 30, 1: 115-148.

GEIS, Irene. (1991), "Chile o el desencanto consensuado". Nueva sociedad, 116: 4-8.

HAYE, Andrés; MANZI, Jorge; GONZÁLEZ, Roberto \& CARVACHO, Hector. (2013), "Teorías infantiles del golpe de Estado en Chile 25 años después”. Psykhe (Santiago) 22, 2: 67-81. HEINZ, Wolfgang \& FRÜHLING, Hugo. (1999), Determinants of Gross Human Rights Violations by State and State Sponsored Actors in Brazil, Uruguay, 
Chile and Argentina: 1960-1990, Netherlands, Martinus Nijhoff Publishers.

HINER, Hillary. (2009), "Voces soterradas, violencias ignoradas: Discurso, violencia política y género en los Informes Rettig y Valech". Latin American Research Review, 44, 3: 50-74.

HITE, Katherine \& COLLINS, Cath. (2009), "Memorial fragments, monumental silences and reawakenings in 21 st-century Chile". Millennium, 38, 2: 379-400.

HOCHMAN, Elena \& MONTERO, Maritza. (2005), Investigación documental: Técnicas y Procedimientos, Caracas, Panapo, 83-84.

HUNEEUS, Carlos. (2014), La democracia semisoberana: Chile después de Pinochet, Santiago de Chile, Taurus.

ÍNIGUEZ-RUEDA, Lupicinio \& ANTAKI, Charles. (1994), "El análisis del discurso en psicología social". Boletin de psicología, 44: 63.

JELIN, Elizabeth. (2013), "Memoria y democracia: Una relación incierta". Politica. Revista de Ciencia Politica, 51, 2: 129-144.

LEY N ${ }^{\circ} 19123$ crea Corporación Nacional de Reparación y Reconciliación, establece pensión de reparación y otorga otros beneficios en favor de personas que señala. Diario Oficial de la República de Chile, Santiago, Chile, 8 de febrero de 1992.

LEY N ${ }^{\circ} 19234$ establece beneficios previsionales por gracia para personas Exoneradas por motivos políticos en lapso que indica y autoriza al Instituto de Normalización Previsional para transigir extrajudicialmente en situaciones que señala. Diario Oficial de la República de Chile, Santiago, Chile, 12 de agosto de 1993.

LEY N ${ }^{\circ} 19588$ que elimina el día 11 de septiembre de cada año como feriado legal y los sustituye por el "Día de la Unidad Nacional”. Diario Oficial de la República de Chile, Santiago, Chile, 11 de noviembre de 1998.

LEY N 19793. Diario Oficial de la República de Chile, Santiago, Chile, 6 de marzo de 2002.

LEY Nº 19980 modifica la Ley $\mathrm{N}^{\circ}$ 19.123, Ley de reparación, ampliando o estableciendo beneficios en favor de las personas que indica. Diario Oficial de la República de Chile, Santiago, Chile, 9 de noviembre de 2004.

LEY N 19992 establece pensión de reparación y otorga otros beneficios a favor de las personas que indica. Diario Oficial de la República de Chile, Santiago, Chile, 24 de diciembre de 2004.

LEY N 20134 concede un bono extraordinario a los Exonerados por motivos políticos que indica. Diario Oficial de la República de Chile, Santiago, Chile, 22 de noviembre de 2006.

LEY N 20405 del Instituto Nacional de Derechos Humanos. Diario Oficial de la República de Chile, Santiago, Chile, 10 de diciembre de 2009.

LEY N ${ }^{\circ} 20885$ crea la Subsecretaría de Derechos Humanos y adecúa la Ley Orgánica del Ministerio de Justicia. Diario Oficial de la República de Chile, Santiago, Chile, 5 de enero de 2016.

LEY N 17288 legisla sobre Monumentos Nacionales; modifica las Leyes 16.617 y 16.719 ; deroga el Decreto Ley 651, de 17 de octubre de 1925. Diario Oficial de la República de Chile, Santiago, Chile, 3 de noviembre de 2017 [ 4 de febrero de 1970].

LIFSCHITZ, Javier Alejandro. (2014), “Os agenciamentos da memória política na América Latina”. Revista brasileira de ciências sociais, 29, 85: 145-158.

LIGUEÑO, Sebastián; PALACIOS, Diego \& SANDOVAL, José. (2018), "Discursos de la vulnerabilidad bajo el gerenciamiento educativo: análisis Ley de subvención escolar preferencial chilena”. Revista de Investigación Psicológica, 19: 207-222.

LIRA, Elizabeth. (2010), “Trauma, duelo, reparación y memoria”. Revista de Estudios Sociales, 36: 14-28.

MADARIGA, Carlos. (2005), "El Informe Valech, otra tarea a medio terminar". Revista Reflexión, 31: 4-8.

MARTÍNEZ, Mónica \& MARTÍNEZ, Fátima. (2018), "Una mirada a los gobiernos de la concertación de partidos por la democracia y sus políticas de justicia transicional en Chile". Ius Comitiälis, 1, 2: 95-107.

OTEÍZA, Teresa. (2003), "De 'la conspiración de silencio' al reconocimiento de voces alternativas. 
Las violaciones a los derechos humanos en Chile según el Informe Valech (2003)”. Revista latinoamericana de estudios del discurso, 9, 1: $87-112$.

OTEÍZA, Teresa \& PINUER, Claudio. (2016), "Des/legitimación de las memorias históricas: Valoración en discursos pedagógicos intermodales de enseñanza básica chilena”. Revista Signos, 49, 92: 377-402.

PASSMORE, Leith. (2016), "The apolitics of memory: Remembering military service under Pinochet through and alongside transitional justice, truth, and reconciliation". Memory Studies, 9, 2: 173-186.

PEÑA-OCHOA, Mónica. (2019), "El análisis crítico de discurso en textos de políticas públicas: lineamientos para una praxis investigativa". $\mathrm{La}$ Trama de la Comunicación, 23, 1:31-46.

PIPER-SHAFIR, Isabel. (2017), Globalización de la memoria: memorias de las victimas, espacios y objetos: Desapariciones. Usos locales, circulaciones globales, Bogotá, Siglo del Hombre Editores/ Universidad de los Andes.

POTTER, Jonathan \& WETHERELL, Margaret. (1987), Discourse and social psychology: Beyond attitudes and behavior, London, Sage.

POTTER, Jonathan \& WETHERELL, Margaret. (1994), "Analyzing discourse", in J. Potter \& M. Wetherell (eds.), Analyzing qualitative data, London, Routledge, 47-66.
RETTBERG, Angelika; UGARRIZA, Juan E. (2016), "Reconciliation: A comprehensive framework for empirical analysis". Security Dialogue, 47, 6: 517-540.

RÍOS, Sandra. (2017), "La memoria social: una herramienta de la justicia transicional en Chile y Corea del Sur". Revista Colombiana de Sociología, 40, 1: 129-147.

ROVIRA, Cristóbal. (2007), "Chile: transición pactada y débil autodeterminación colectiva de la sociedad". Revista Mexicana de Sociología, 2, 69: 343-372.

RUBIO, Graciela. (2013), "Memoria, ciudadanía y lo público en la elaboración del pasado reciente en la experiencia chilena”. Memoria y sociedad, 17, 35: 164-183.

RUDERER, Stephan. (2010), "La política del pasado en Chile 1990-2006: ¿un modelo chileno?”. Universum (Talca), 25, 2: 161-177.

SEPÚLVEDA, Daniela. (2014), "Memoria y Reparación: El Tratamiento Institucional a las Víctimas de Violación de Derechos Humanos en Chile”. Política, Revista de Ciencia Política, 52, 1:211-227.

SIERRA, Lucas. (2005), "Reabrir y Cicatrizar: Notas sobre el Informe Valech y sus reacciones". Anuario de Derechos Humanos, 1: 157.

VÁZQUEZ, Félix. (2001), La memoria como acción social: relaciones, significados e imaginario, Barcelona, Paidós. 


\section{LA DOSIFICACIÓN DEL PASADO: LA MEMORIA EN LAS POLÍTICAS OFICIALES DE REPARACIÓN CHILENAS}

Juan Carlos Arboleda-Ariza, Gabriel Prosser Bravo

Palabras claves: Políticas de la reparación, Memoria social, Dictadura chilena, Esteganografía de la memoria.

Debido a la violencia cometida durante la Dictadura, el Estado chileno debió generar medidas de reparación que permitieran resarcir la dignidad nacional y de las víctimas. En este contexto, se crearon dispositivos jurídicopolíticos, en el marco de la Justicia Transicional, orientados a consolidar la memoria social. El objetivo del presente texto fue el de comprender cómo se construye la memoria dentro de las políticas de reparación. Se realizó un análisis del discurso de las normas que regulan la reparación en Chile, dando por resultado cuatro repertorios interpretativos: repertorio de la reparación como verdad oficial; repertorio instituciones; repertorio archivo y; repertorio conmemoración. Se concluye que estas políticas configuran la memoria de la Dictadura en Chile como una esteganografía en una serie de piezas que vienen dosificadas por las normas. En este sentido, la institucionalización del recuerdo ha definido quienes, cómo, cuándo y dónde recordar en Chile.

\section{A DOSAGEM DO PASSADO: A MEMÓRIA NAS POLIITICAS OFICIAIS DE REPARAÇÃO DO CHILE}

Juan Carlos Arboleda-Ariza, Gabriel Prosser Bravo

Palavras-chave: Políticas de reparação, Memória social, Ditadura chilena, Esteganografia da memória

Devido à violência cometida durante a ditadura, o Estado chileno teve que criar medidas de reparação que ressarcissem a dignidade nacional e das vítimas. Nesse contexto, no âmbito da Justiça Transicional foram criados dispositivos político-jurídicos orientados a consolidar a memória social. O objetivo do presente trabalho é o de compreender como se constrói a memória nas políticas da reparação. Foi realizada uma análise de discurso das normas que regulam a reparação no Chile, a qual resultou em quatro repertórios interpretativos: repertório da reparação como verdade oficial; repertório instituiçôes; repertório arquivo e; repertório comemoraçâa. Conclui-se que essas políticas configuram a memória da ditadura no Chile como uma esteganografia em uma série de peças que vêm dosificadas pelas normas. Nesse sentido, a institucionalização da recordaçáo tem definido quem, como, quando e onde recordar no Chile.

\section{THE DOSAGE OF THE PAST: MEMORY IN CHILE'S OFFICIAL REPARATION POLICIES}

Juan Carlos Arboleda-Ariza, Gabriel Prosser Bravo

Keywords: Reparation policies, Social memory, Chilean dictatorship, Memory steganography.

Due to the violence committed during the dictatorship, the Chilean State had to create reparation measures that would refund national dignity and the victims. In this context, within the scope of Transitional Justice, politicallegal devices were created to consolidate social memory. The aim of the present study is to understand how memory is built in reparation policies. A discourse analysis of the rules that regulate reparations in Chile was carried out, resulting in four interpretative repertoires: a reparation repertoire as an official truth, an institutions repertoire, a file repertoire and a celebration repertoire. We conclude that these policies configure the memory of the dictatorship in Chile as a steganography in a series of pieces that have been dosed by the rules. In this sense, the institutionalization of remembrance has defined who, how, when and where to remember in Chile.
LE DOSAGE DU PASSÉ: LA MÉMOIRE DANS LES POLITIQUES OFFICIELLES DE RÉPARATION DU CHILI

Juan Carlos Arboleda-Ariza, Gabriel Prosser Bravo

Mots-clés: politiques de réparation; mémoire sociale; dictature chilienne; sténographie de la mémoire.

Suites aux violences exercées pendant la dictature, l'état chilien a dû créer des mesures de réparation pour dédommager la dignité nationale et celle des victimes. Dans ce contexte, des dispositifs politico-juridiques ont été mis en place dans le cadre de la justice transitionnelle afin de consolider la mémoire sociale. L'objectif de ce travail est de comprendre la construction de la mémoire dans les politiques de réparation. L'analyse de discours des normes qui régulent la réparation au Chili a mis en évidence quatre répertoires interprétatifs: répertoire de la réparation en tant que vérité officielle; répertoire institutions; répertoire archives; et répertoire commémoration. Les résultats montrent que ces politiques configurent la mémoire de la dictature au Chili comme une stéganographie dans une suite de pièces dosées par les normes. Dans ce sens, l'institutionnalisation du souvenir définit qui, comment, quand et où se rappeler au Chili. 